\title{
Voice Assistant and Route Optimization System for Logistics Companies in Depopulated Rural Areas
}

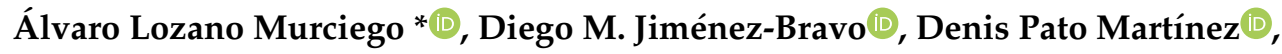 \\ Adrián Valera Román ${ }^{D}$ and Gabino Luis Lazo $\mathbb{D}$ \\ Expert Systems and Applications Lab, Faculty of Science, University of Salamanca, Plaza de los Caídos s/n, \\ 37008 Salamanca, Spain; dmjimenez@usal.es (D.M.J.-B.); denispato679@usal.es (D.P.M.); \\ adrianvalrom.usal@usal.es (A.V.R.); gabinoluis@usal.es (G.L.L.) \\ * Correspondence: loza@usal.es; Tel.: +34-923-294-500 (ext. 6072)
}

Received: 10 June 2020; Accepted: 30 June 2020; Published: 3 July 2020

check for updates

\begin{abstract}
Nowadays, the depopulation of Europe's rural areas and the ageing of the population in these areas has led to the disappearance of basic services such as supermarkets, fishmongers, household goods, etc. In response to this problem, there are European and local initiatives to mitigate these effects by investing in Internet and Communication Technologies (ICT) infrastructure and logistics services for these areas with the aim of moving services to these isolated areas. The problem with these services lies in the difficulty of the use of ICT by aged people due to digital divide and, at the same time, the high cost in human resources, time, vehicles, and fuel presented by delivery services in these areas. This work presents a system that combines the use of intelligent personal assistants (IPA) to facilitate access to information technology for aged people to place orders and the optimization of delivery routes in a rural environment by a socially-oriented logistics company. This work presents a case study based on the fixed delivery routes of a social logistics company and describes how the proposed system could help in the optimization of routes and the reception of orders by the elderly via ICTs thanks to the use of IPAs. Subsequent to the study, route cost savings have been observed as well as the homogeneity of the cost of the routes it can provide compared to a static and predefined fixed route planning. This study also shows how the IPAs make possible the reception of orders in real time placed by the older adults from their homes. This work is aimed at improving the sustainability of services in depopulated rural areas while saving costs for the logistics companies that perform these services.
\end{abstract}

Keywords: intelligent personal assistant; voice assistant; route optimization; vehicle routing problem; social-logistic companies; depopulated areas; older adults

\section{Introduction}

At present, $20 \%$ of the European population is over 65 years old and, according to the "Ageing Europe" report [1] of the European Commission, this percentage is expected to increase to $23.8 \%$ by 2030. Besides, a recent Eurostat analysis [2] highlighted that the population of certain regions in Europe, such as Castilla y León (Spain), is mainly elderly people.

At the same time, rural areas in southern Europe like the one mentioned previously are experiencing a depopulation [3] which is affecting them and aggravating their situation. This depopulation is causing the closure of local services and businesses in local towns due to their lack of customer demand.

This means the extinction of basic services (supermarket, clothing store, fruit shop, parts store, etc.) in an increasing number of towns in Europe where they were previously provided and, consequently, people of these towns are compelled to travel to nearby towns to access these services. This situation worsens if these people are aged and the need to travel to other towns prevent them from access to basic 
services. This problem could easily be addressed if interurban transport were available during the week in rural areas. However, this type of transport is not sustainable due to the low population who would use it. Besides, many of the people living in these areas are aged people and may have health problems, making it difficult to use private transport to access these services in near towns. These problems reduce the autonomy of the elderly living in towns and simultaneously cause the young population to continue migrating to urban centers, further aggravating the situation in these areas.

Linked to this is the problem of the digital divide in the rural areas of Europe. According to a report of the European Parliament [4], there are issues of high-speed internet access in rural areas, and yet 58 million European citizens between the ages of 16 and 74 have never had access to internet services. To solve these problems, the European Union has proposed initiatives such as the European Network for Rural Development [5], which seeks to improve the rural environment with new approaches in entrepreneurship and rural development, or other initiatives aiming to provide technological infrastructure like Internet access to small towns, such as WiFi4EU [6,7].

The provision of Internet and Communication Technologies (ICT) infrastructures as well as the improvement of transport and the creation of goods logistic services that allow people in these rural localities to continue to access the services they previously had are key factors in the recovery of such services in these depopulated areas. All this without the need to move to other nearby villages where these services still exist.

On the one hand, the existence of logistics companies that bring goods and services from urban areas to these rural areas becomes a fundamental point to provide them with the services they have lost. However, the main disadvantage for these logistics companies is the cost of time, human resources, vehicles, and fuel required to offer home delivery services in isolated and extensive rural regions where traveling supposes a high cost, which could increase the final price for the customer. Therefore, it is necessary to investigate ways of improving the efficiency of these companies by optimizing delivery routes to reduce associated costs for maintaining competitive prices.

On the other hand, easy access to ICTs is needed so that elderly people of these villages can use them. Besides, this kind of population needs to be provided with ICT-based services to reduce the impact of a lack of these services.

From scientific and technological literature, many solutions have been presented in different fields. For example, in the health sector, medical teleassistance has been developed, as well as security systems based on sensors which are installed in elderly people's houses and/or on wearable devices to monitor their health condition and send alarms if needed.

Furthermore, research on how to facilitate access to ICTs for these people in a simple way is currently being carried out. One of the Human-Computer Interfaces (HCI) being researched [8] for aged people to use it is Intelligent Personal Assistant (IPA) [9]. The aim is to employ these IPAs as a conversational interface to make the learning curve of the use of new technologies as light as possible. This type of assistant is being greatly accepted by aged people and scientific literature is increasingly presenting works that employ IPA to offer digital services to the elderly and to be their means of communication with home automation devices such thermostat, lighting, or even the doorbell.

To respond to the problems raised, this work presents an innovative system that combines the aspects presented previously: the use of IPAs for access by aged people to place orders with a food delivery company and the optimization of delivery routes for this company to minimize its costs. This work is framed in the EMERITI project, which aims to integrate the Voice Assistants (VAs) in the daily life of the elderly by trying to improve the interaction with their environment and making it easier to access the technology via the VAs.

This article has the following structure: Section 2 presents a summary of the state of the art regarding the use of VAs, to improve elderly daily life and a summary of the key concepts of route optimization techniques used in the case study. Section 3 describes the proposed system as well as its main elements. Section 4 presents a case study where a simulation is developed, taking real scenario data from a social logistics company, and how this system could improve its current logistics operation 
costs. Section 5 shows and presents a discussion of the results obtained from the use case of the system. Finally, Section 6 details the conclusions of the work and points out the main lines of open research along with possible future work.

\section{Background}

This section details the state of the art of the devices, technologies, and techniques used in the proposed system. The IPAs are therefore presented in the context of older adults and the optimization techniques used in the literature for the optimization of goods and order transport vehicle routes and their application in this work.

\subsection{Voice Assistants and the Elderly}

VAs, also known in the literature as a kind of IPA, are a kind of software that provides a verbal communication interface to the end-user and uses artificial intelligence techniques, such as speech recognition, natural language processing, dialogue systems, and speech synthesis, to interact with the user. The user can talk to the software to make it do an action and then the software will use these techniques to process the information received and complete the requested action if possible. These assistants also send the information (answers) through a conversation. From the scientific literature, the systematic review performed by De Barcelos et al. [10] presents a general architecture of VAs. Diagram of Figure 1 summarizes the overall functioning of these systems. Figure 1 shows how these systems employ different techniques of artificial intelligence to complete each step involved in the VAs normal operation.

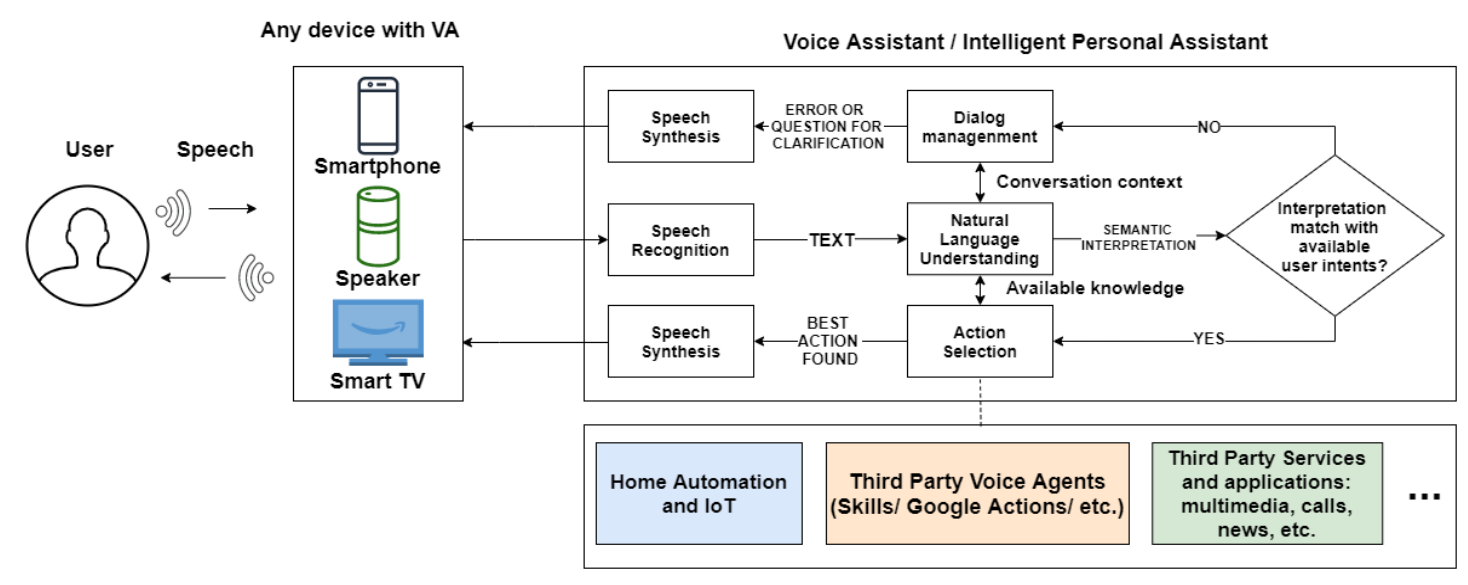

Figure 1. Main Architecture of Voice Assistants.

First, the user initiates a conversation with the VA manually via a button or verbally via the pronunciation of a keyword which acts as a wake word for the device. The voice assistant using speech recognition techniques identifies this keyword and begins the conversation waiting for a user voice command.

Secondly, the user pronounces a sentence containing the command they want to request from the VA. Through speech recognition, this sentence is translated into text and later this text is analyzed with Natural Language Processing (NLP) techniques. The main objective of this stage is to match the user's sentence meaning and the actions available to the assistant, also considering the current context of the conversation. If it cannot be associated with a specific intent, either because the semantics of the phrase have not been correctly extracted or because such an action is not available, this result will be transmitted to the user verbally using text to speech techniques (TTS). On the contrary, if the semantic interpretation of the phrase matches any available action, the VA will execute the most suitable action and answer the user through TTS. 
Actions that can be performed by the VAs range from the functionality that these same assistants implement to the use of multimedia services or external calls, invoking other third-party software agents (e.g., Google Actions or Alexa Skills, depending on the development platform) and even interacting with home automation and Internet of Things (IoT) platforms by acting directly on connected devices or retrieving information from them

The variety of actions that are possible with VAs is one of the factors that have led to their increasingly widespread use [11]. Research on the application of VA in older adults' home environment has become relevant in the scientific literature in recent years and has been conducted from different approaches. Some of the latest works on VA use are described below.

Studies such as that of Kowalski et al. [12] or that carried out by the Front Porch Center for Innovation and Wellbeing (FPCIW) [13] consisted of distributing Google Home and Amazon Echo devices among a specific number of older adults to subsequently measure user satisfaction through surveys after a while. Work such as that of Reis et al. [14] examined the use of various assistants and their main functionalities to assist the elderly. The authors concluded that there is still work to do to improve ineffective communication between VAs and older adults.

For these reasons it is necessary to research how to integrate these VAs in the daily life of older adults, transforming the VAs into useful tools for accessing to ICTs in this kind of populations.

It is worth noting how the issues of the digital divide [4] related to lack of digital skills can be addressed with IPAs. However, these technologies require an ICT infrastructure in rural areas in order to function and for citizens to be able to take full advantage of them. For this reason, initiatives such as WiFi4EU [7] and local policies to provide infrastructure in these areas are essential.

\subsection{Vehicle Routing Problem}

One of the most representative expenses in any logistics company is the one associated with the routes made by a fleet of vehicles that have to deliver or pick up certain products in different geographical locations. Formally, in the scientific literature, this type of problem is known as the Vehicle Routing Problem (VRP) [15,16], and it includes a set of problems intended to find several routes for a group of vehicles that depart from a common geographical point known as a depot. These vehicles must satisfy the demand of customers who are geographically distributed. The objective of VRP and its variants is to find distribution or collection routes for those customers with a certain demand while reducing the cost of these (in terms of time, distance, etc.) which start and end at the same depot. The original VRP is also known as the Capacitated Vehicle Routing Problem, which establishes that all vehicles have the same maximum capacity that the routes must not exceed as a restriction. As new restrictions are added to the original problem, new variants of the problem emerge $[16,17]$ that come closer to the real scenario of a logistics company. There are variants with time windows (VRP with Time Windows [18] or VRPTW), heterogeneous fleets (Heterogeneous Fleet VRP or Mixed Fleet VRP [19]), pickups and deliveries (VRP with Pickups and Delivery [20]), among others. Figure 2 shows a scheme that describes the elements of the problem.

The VRP and its derivatives are NP-hard problems, which means that the bigger the problem is the greater the computational complexity to resolve them becomes. In the scientific literature [21], several solution searching methods have been proposed for these problems, such as: (1) the Exact Approaches, which explore exhaustively the search space until they find the optimal solution; these can be branch and bound [22] or branch cut and price [23]; (2) heuristic methods, which perform a restricted exploration of the Search space and usually deliver good quality results in very limited computing times [24]; and (3) meta-heuristic methods, which are generic methods of exploration in the solutions space for searching and optimization problems. These methods provide a design line adaptable to each context and they can generate more efficient algorithms. These algorithms-Ant algorithms [25], Constraint Programming [26,27], Genetic Algorithms [28], and Tabu Search [29,30], among others-usually work better than heuristic methods. Many of these techniques are available 
in VRP solving frameworks such as OR-TOOLS [31], VROOM [32], some of them are employed in this work.

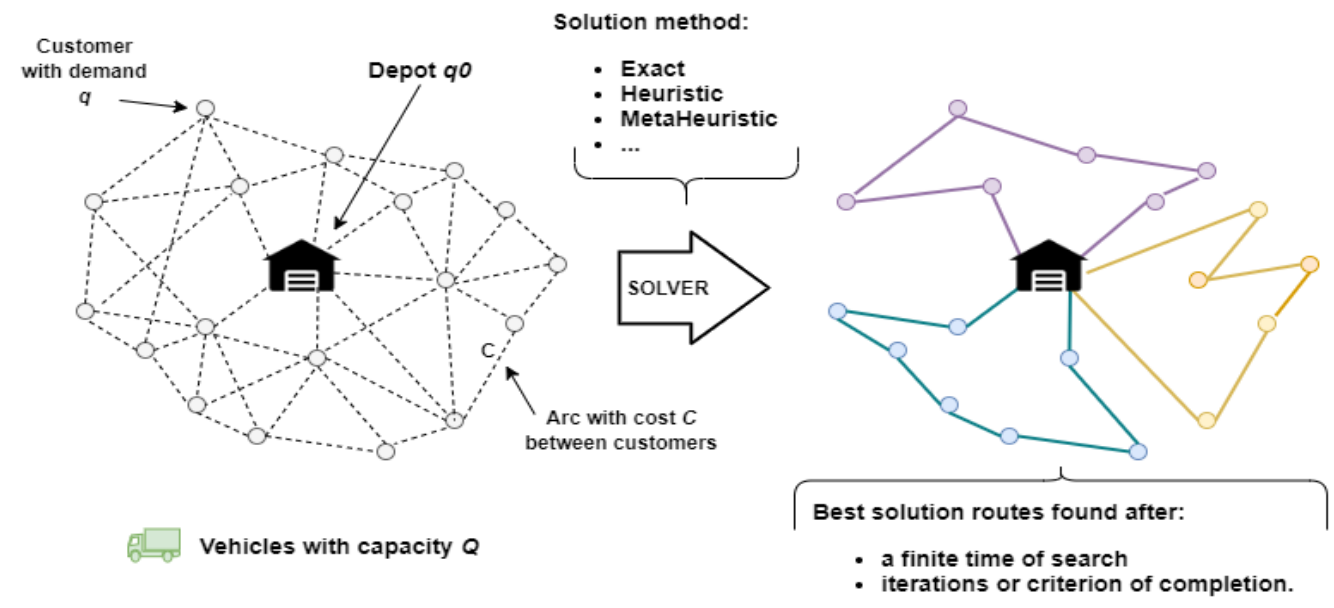

Figure 2. This figure shows on the left a schema of the input parameters of a Capacitated Vehicle Routing Problem (CVRP) problem and, on the right, the output route solutions obtained by a solver.

\section{Proposed System}

This section describes the elderly-oriented order processing system using IPAs combined with a system for the management of these orders and the optimization of vehicle routes for the logistics company. The proposed system aims to integrate the IPAs as an element of access to ICT for the elderly thanks to their natural and accessible communication interface.

\subsection{Architecture}

Next, the architecture of the system for obtaining orders using IPAs and its integration with a management system for delivering orders and optimizing vehicle routes for the logistics company is described. Figure 3 shows a general diagram of the architecture showing the main elements of the proposed system.

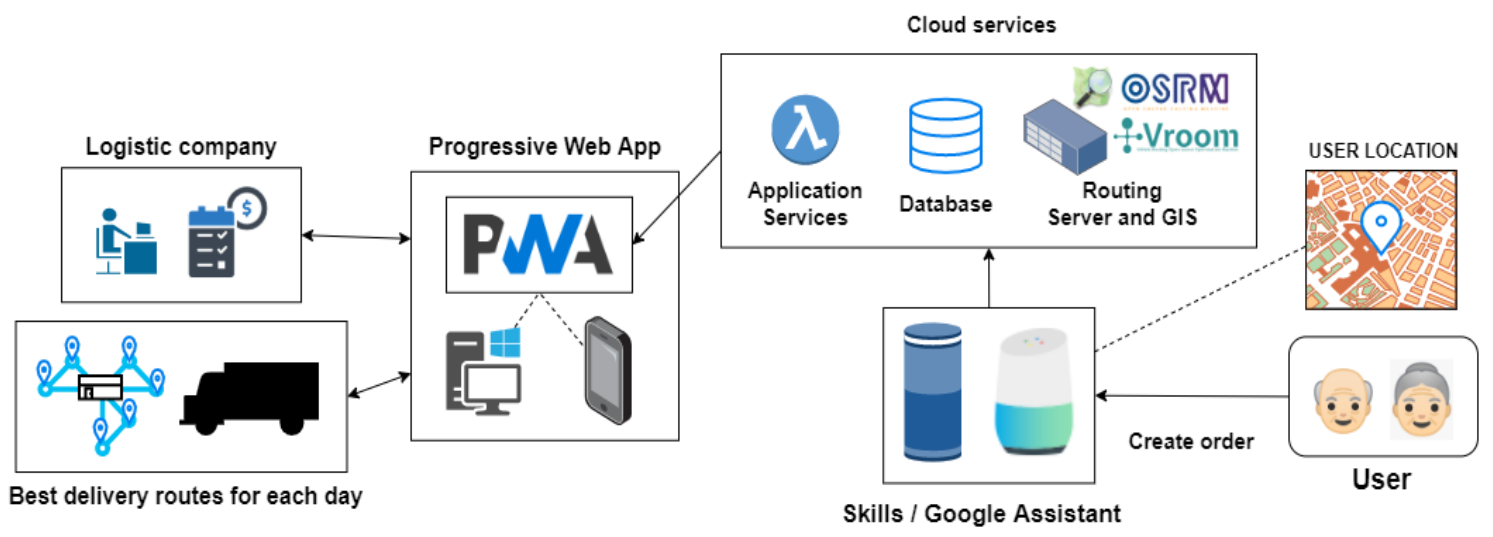

Figure 3. Main diagram of the proposed system architecture.

The right side of Figure 3 shows the access that the elderly person would have to the system using an IPA available in any of the devices that allow it: a SmartTV, a smart speaker, a mobile phone, etc. The user, through a dialogue with the assistant, places an order with different items for the next available delivery date for the user location. The user geographic location is at first collected automatically by the IPA, but it can be changed if requested. This order will be sent to a real-time database- the 
central part of Figure 3-and then processed by a set of cloud services that are listening for changes in that database. These cloud services include storage services, notification services, and Geographic Information Systems (GIS) services for the calculation of delivery routes. These services are used by a Progressive Web App (PWA) available to the logistics company team, where employees can add new orders, review existing ones, generate delivery routes, and then navigate those routes. The decision to implement this part as a PWA facilitates its use from different platforms (Desktop/Mobile/Web) and allows the use of notifications. The operation of the previously described elements is detailed below.

\subsection{Voice Assistant Agent}

The VA agent is the software implemented for the VA that will establish a conversation with the user. In the proposed system, Google Assistant has been used as a development platform and the voice assistant agent has been implemented as a Google Action. These software agents are activated through the assistant with a phrase like "Ok Google talk to $<$ name of agent $>$ " and at this moment the conversation flow will be transferred to the software agent $<$ name of agent $>$. This VA agent will collect the items from the user order through a conversation. On its first use, the VA agent will request the user personal information and permissions so that these data can be employed in the order management system.

Figure 4 illustrates a sequence diagram of several of the VA agent available options regarding the processing of an order: (1) add a product to the list, (2) delete a product from the list, (3) display a product from the list, (4) delete the entire list. For simplicity we have excluded from this figure all the other options like finishing the order and options for checking the current order or the last orders.

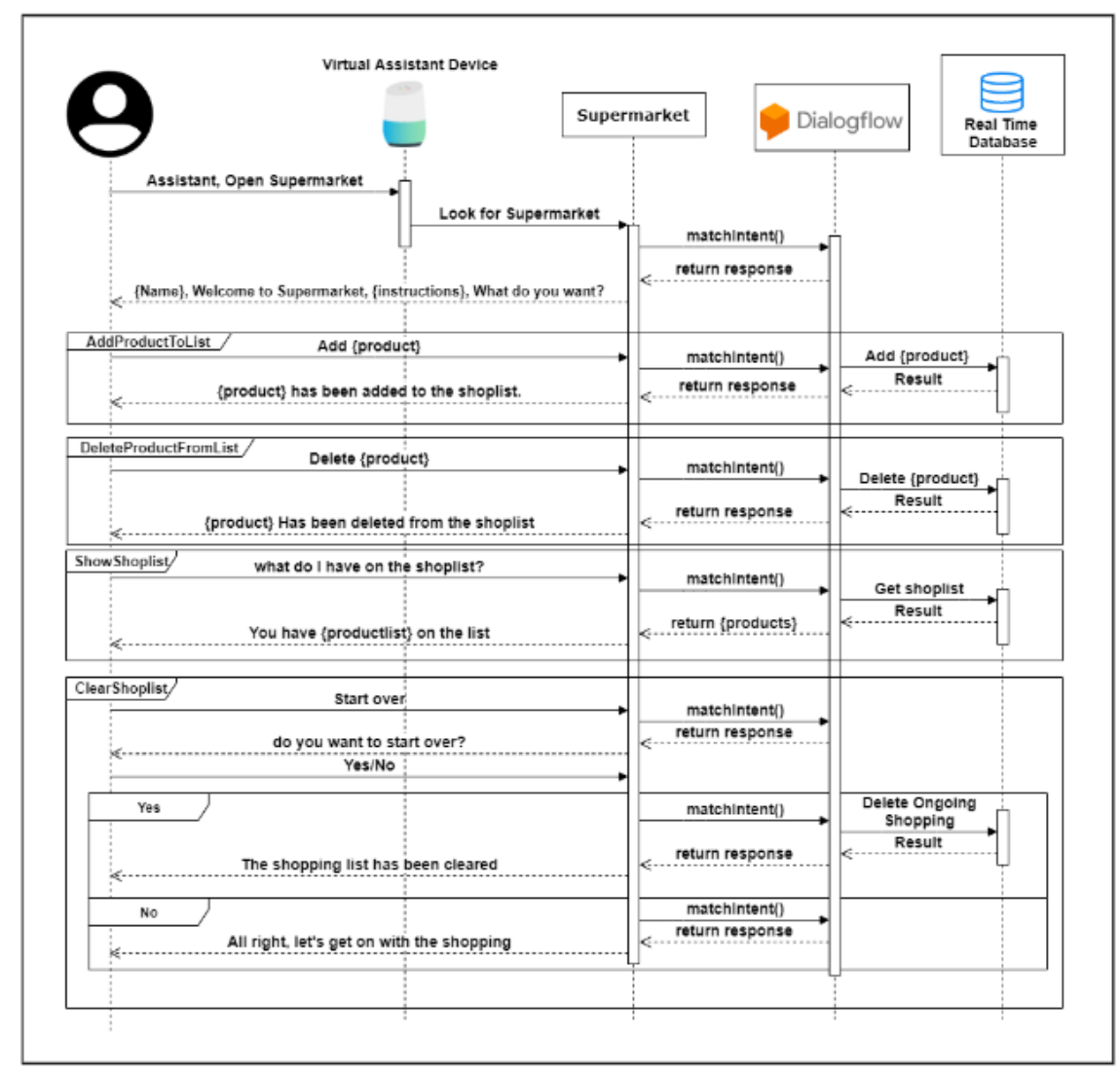

Figure 4. Voice assistant cart list dialog sequence diagram.

Once the VA agent is invoked, the user can perform any of the previously described actions in a conversation. The device with the IPA will receive the audio from the user, which will subsequently 
be processed and transformed to text with TTS techniques. After this processing, these sentences are processed with NLP techniques via the Dialogflow platform, used in previous works for the creation of conversational bots [33,34], which will manage the conversation and finally associate it with a specific action of the ones previously explained. If it is not possible to associate the user phrase with any of the previous actions, the agent will ask the user again. Depending on the action performed, the real-time database of the order logistics system will be modified (creating orders, adding products, deleting, updating ... ). Once the user completes the order, a system cloud service will detect this new order in the real-time database and notify it to the logistics company via PWA application. The user can later check the status of the order by making a query to the Voice Assistant agent.

\subsection{Progressive Web App}

As shown in the initial system architecture diagram, a progressive web app has been designed and implemented for the company that manages and delivers the orders. This concept of applications [35], created by Google, aims to unify web development and make it supported with different platforms, thus speeding up development and obtaining native application features, such as push notifications. This application can process orders received by IPAs, create new orders, and calculate vehicle routes, as well as enable navigation of these routes. Everything is done using cloud services that implement data storage, processing services, and route calculation. The sections and functionality of the PWA are described below.

\subsubsection{Order Management}

The main screen of the application-Figure $5 \mathrm{a}$-includes a floating button on the bottom right corner of the screen that shows the different options available (orders, products, and routes) when clicking it. All these options are contextual following the date selected on the top right corner-Figure $5 \mathrm{~b}$. On the top left corner, there is a menu button that opens the user profile, which can be configured, as well as other options related to route calculation, detailed in Figure $5 \mathrm{c}$.

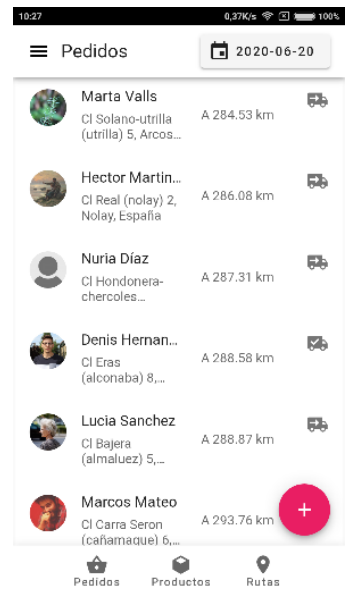

(a)

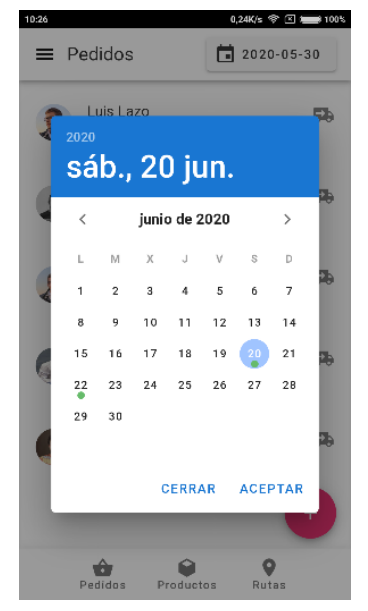

(b)

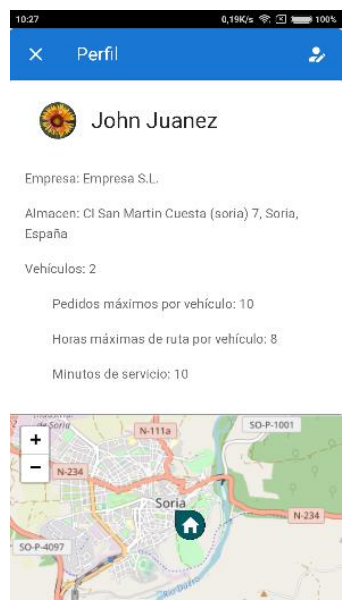

(c)

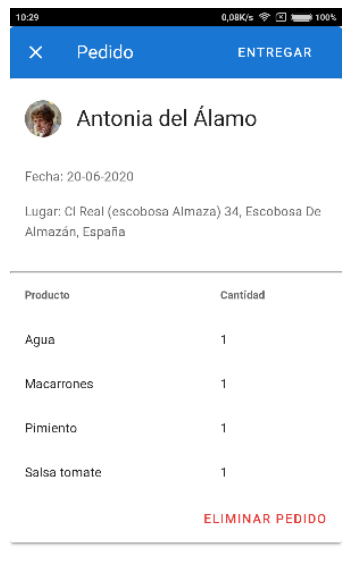

(d)

Figure 5. Progressive Web App user interface: (a) order list (b) day selection (c) user profile (d) order detail.

On the bottom bar options of the main screen, the left one (Orders) allows the user to manage the orders received by the IPA and add new orders obtained by other means, such as telephone or e-mail of the company to the delivery journey. It also allows the user to display details of each order-Figure $5 \mathrm{~d}$. The central product section provides a complete list of products required for the day and the right option is dedicated to the calculation of vehicle routes for that day. 


\subsubsection{Route Calculation and Optimization}

For each day, there are several customers, distributed geographically, each one of them with an order and a series of products associated with it (demand). Simultaneously, the company has a logistics center (depot) from which a certain number of vehicles will leave to satisfy the demand of these customers. The geographic location of this center can be modified in the profile section shown in Figure $5 \mathrm{c}$. In this same section, the number of vehicles that the company has can be specified, as well as the capacity of orders that each vehicle can serve, and the service time per order. Initially, the problem is approached with limited restrictions, such as a homogeneous fleet of vehicles and homogeneous service times per order. This information together with the geographic information of each order for a specific day defines the parameters of a VRP problem. To find the solution to this problem (a set of routes that minimizes the total cost), a cloud service monitors the changes in the real-time database that happen in the parameters of this problem, making new calculations of the routes for that day from the changes detected in the input parameters of the problem. This cloud service interacts with another cloud service responsible for route calculations that implement the VRPTW calculation algorithms and has access to a routing engine with geographic information from OpenStreetMaps. Figure 6a shows a diagram of the communication and routing process for the described cloud services. The route optimization system has been implemented using VROOM [32], which is an open-source software developed in $\mathrm{C}++$ to solve vehicle routing problem variants such as VRPTW. Vroom relies on data from OpenStreetMaps [36] for geographic information and data from a routing engine, in this case Open Source Routing Machine (OSRM) [37] has been used to obtain the cost matrices between the different nodes. Regarding the algorithm used by VROOM to solve VRPTW problems, they combine a dedicated clustering heuristic using spanning trees for creating clusters and monitoring constraints, then it solves a TSP instance for each cluster, and finally it applies a later phase of local search to improve the solutions found [38]. We have selected this platform for the proposed system because is completely open source and it scales for bigger VRPTW instances.

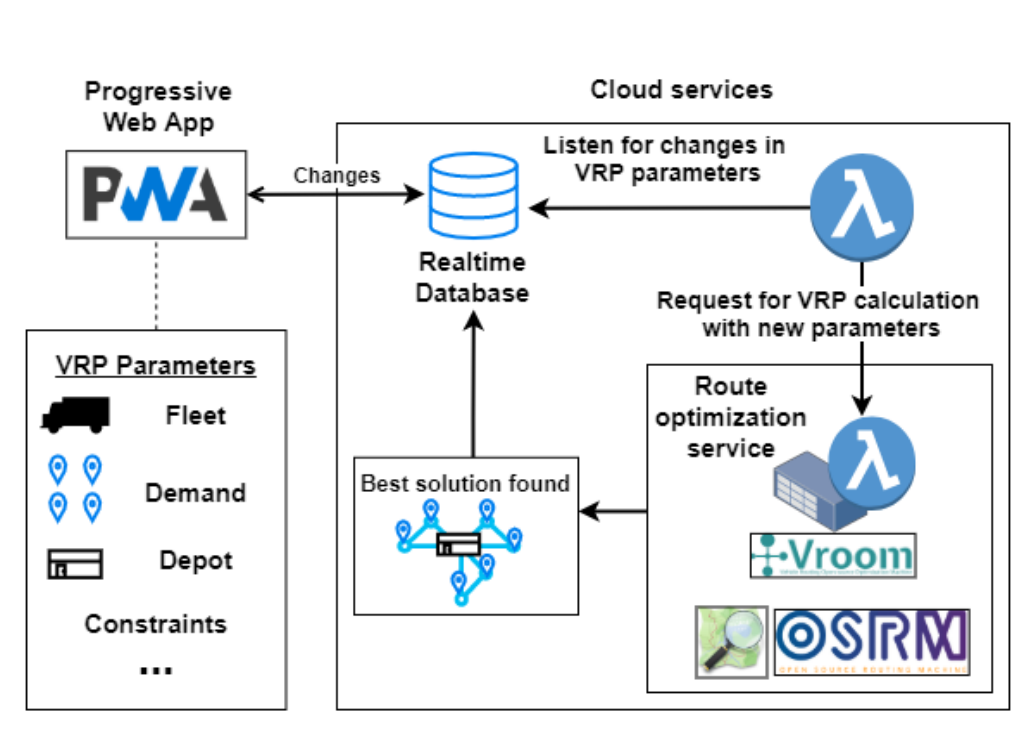

(a)

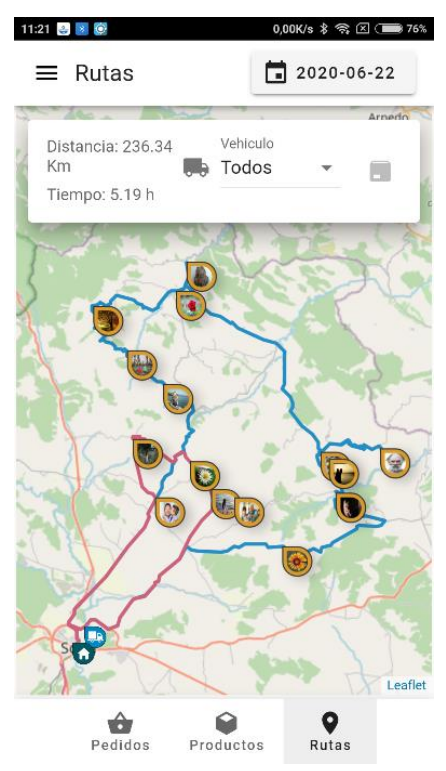

(b)

Figure 6. (a) Cloud services interaction for route calculation (b) route section UI in the PWA.

Finally, the calculated route is stored in the database to be later available in the route section (Figure 6b). At this point, the user can consult the routes for each of the vehicles as well as the orders and products to be loaded in the vehicle. 


\subsubsection{Route Navigation}

Once the delivery journey starts, the driver can select the route to take by using a drop-down menu and then clicking on the floating button at the bottom right (Figure 7a). This will transfer the waypoints of the route to a link that can be opened with Google Maps Navigation (Figure 7b), where the route can be navigated. As the route advances, the operator will be able to mark the orders that have been delivered in the route section, which will be marked in green on the map, and a new icon will be displayed. These changes are updated in real-time in the applications of the rest of the company administrative users, allowing them to monitor the delivery schedule.

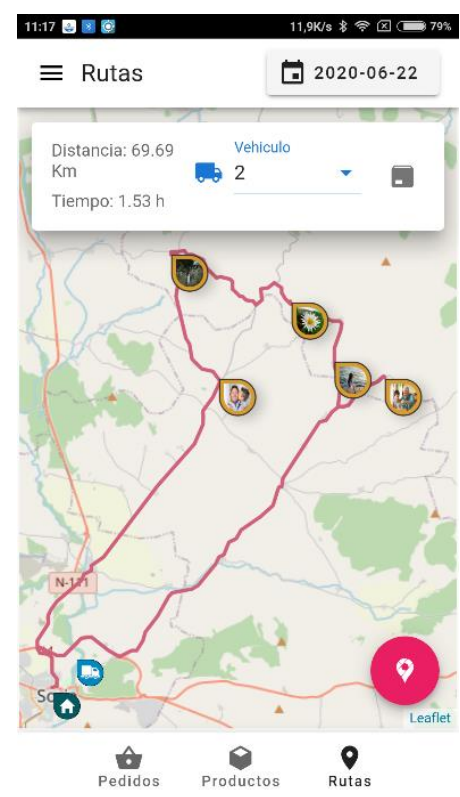

(a)

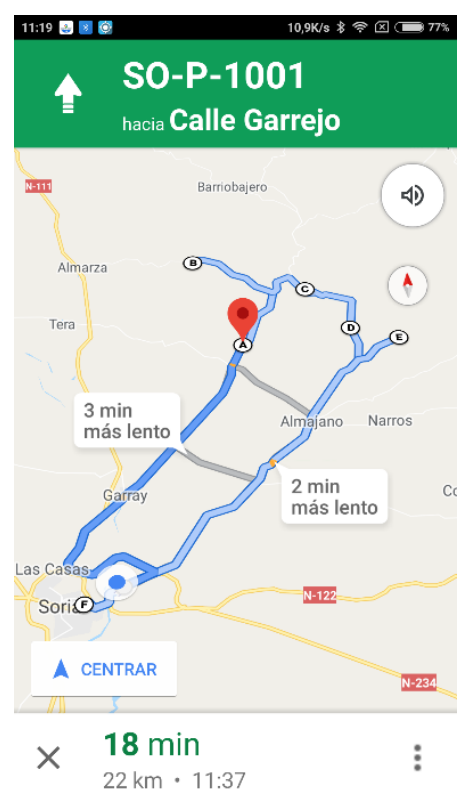

(b)

Figure 7. Route selection (a) and route navigation in the Google Navigation application after pressing button (b).

\section{Case Study}

This section presents a simulation case study that sought to evaluate the effectiveness of the previously proposed system in a real setting where a company is dedicated to the reception of orders in depopulated rural areas. The system will address the placing of such orders by customer in the department stores and the weekly distribution of such orders via route optimization.

The company taken as basis of the case study regularly operates a series of routes certain days of the week in two depopulated regions of Castilla y León: Soria and Burgos. The population of the villages where they operate is shown in Figure 8a (Soria villages population) and Figure 8b (Burgos villages population). As shown in both charts, these are two depopulated rural areas where most towns have fewer than 250 inhabitants.

In the region of Burgos they operate twice per week, Tuesdays and Wednesday (Figure 9a), and in the region of Soria, four times per week, from Tuesday to Friday (Figure 9b). These routes meet the demand for services from a number of populations which have gradually lost them due to depopulation and whose population is aged. 


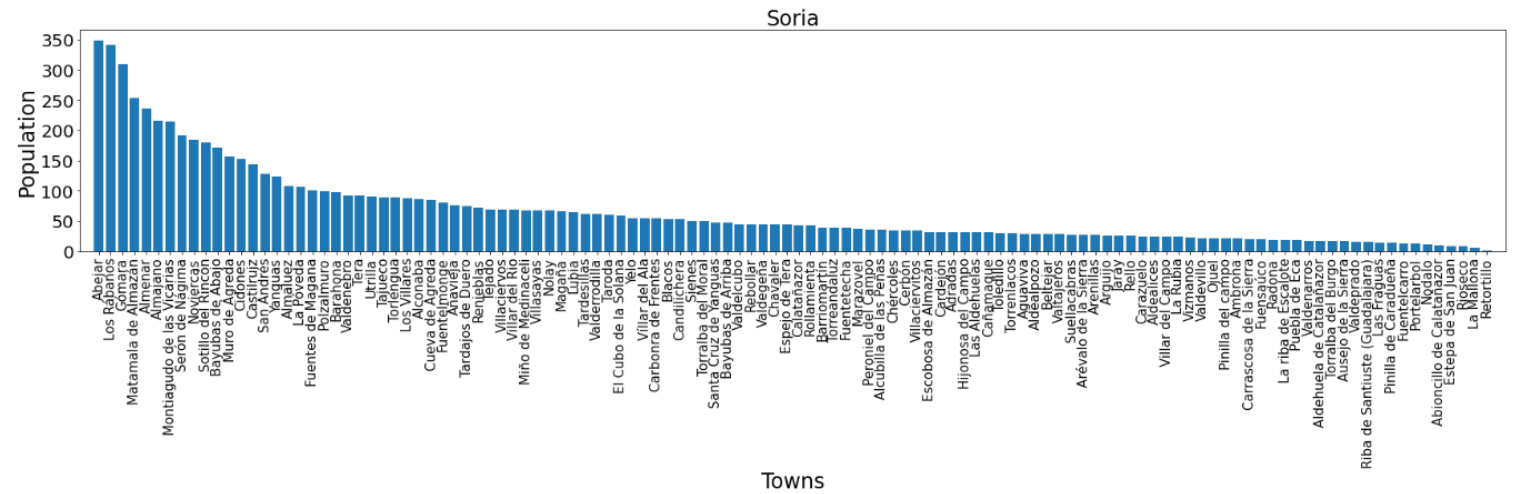

(a)

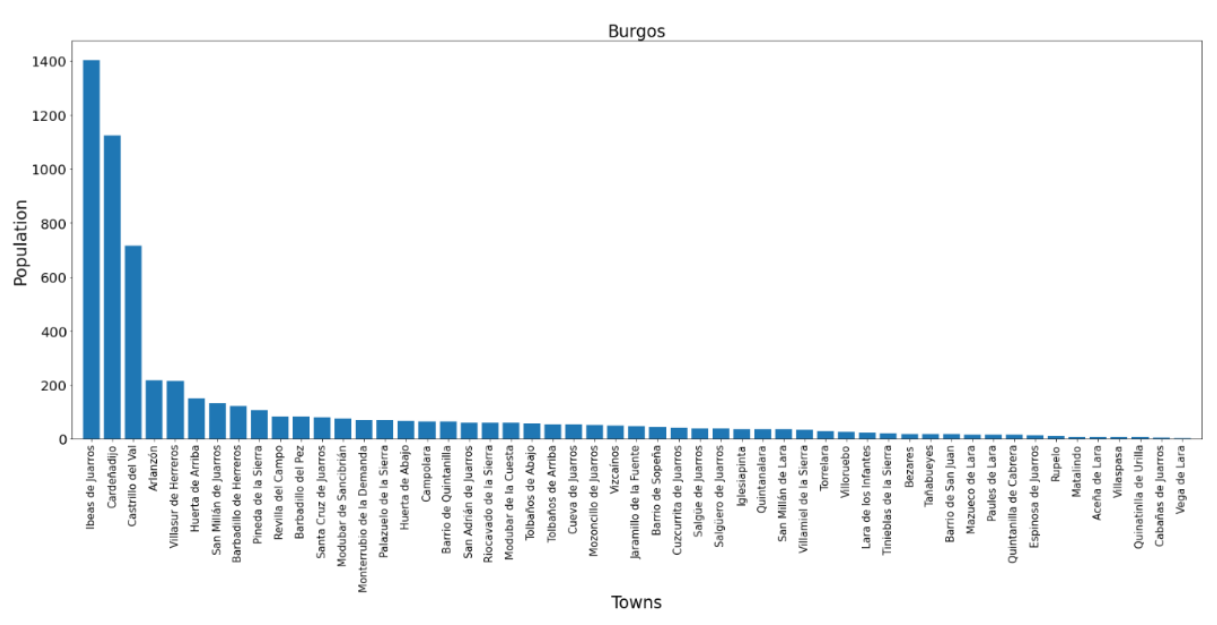

(b)

Figure 8. Population of (a) Soria towns and (b) Burgos towns where the company operates.

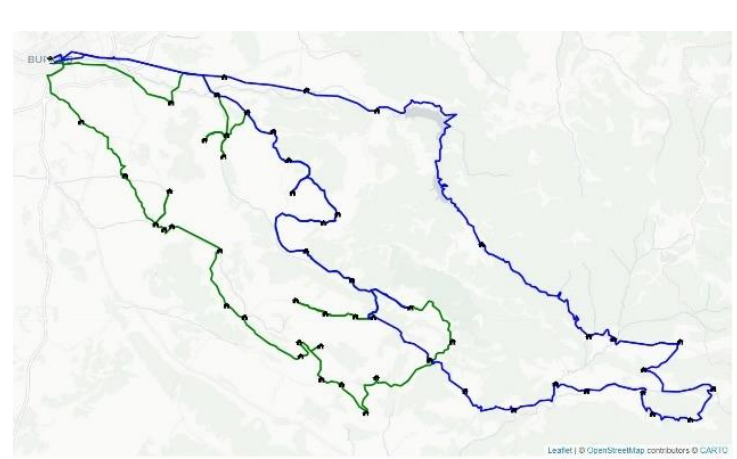

(a)

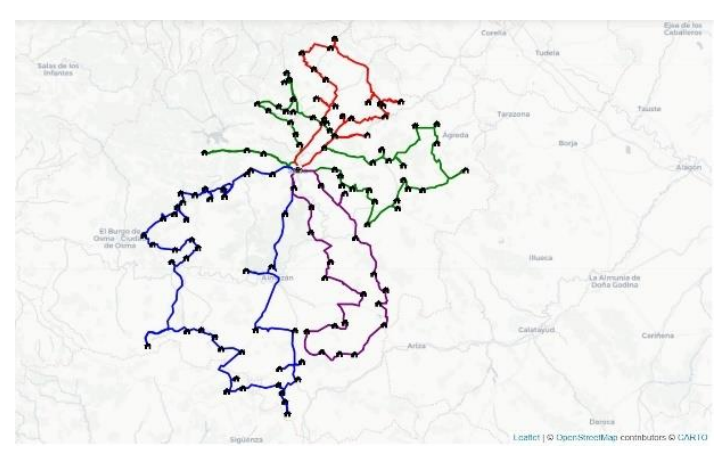

(b)

Figure 9. Fixed routes performed every week (a) Burgos (b) Soria.

According to the information published on their website [39], they initially designed several fixed routes. Table 1 shows these routes together with their respective costs in distance and time by car employing the shortest route. They also established as a means of receiving orders a mailbox in each town, a telephone number, an email address, and social networks such as Whatsapp and Facebook. This case study sought to evaluate how the system proposed in this work could benefit a company of 
these characteristics, regarding both the optimization of the delivery routes and the way of receiving orders from customers through the new IPAs.

Table 1. Current routes defined by logistic company.

\begin{tabular}{ccc}
\hline Ruta & Distance $\mathbf{( k m )}$ & Time $^{\mathbf{1}} \mathbf{( h )}$ \\
\hline Burgos1 & 160.18 & 6.93 \\
Burgos2 & 184.19 & 6.2 \\
Soria1 & 323.50 & 9.75 \\
Soria2 & 387.76 & 11.01 \\
Soria3 & 201.04 & 5.28 \\
Soria4 & 203.13 & 5.83 \\
\hline
\end{tabular}

${ }^{1}$ With a homogeneous service time cost of 5 min per visited town.

\section{Route Optimization: Static Approach Versus Dynamic Approach on Route Calculation}

From a static route calculation approach, delivery routes are calculated only once, remain unchanged and are covered weekly throughout the year. Following the case study proposed, every group of towns is assigned to a certain day of the week. This approach results in the restriction of times that people can place an order, from week to week, but it also facilitates the logistics operator task regarding the preparation of the orders and establishes a relationship with costumers on a weekly basis, which is a positive factor in this specific case.

However, delivery routes planned from a long term static approach are effective when the customer demand remains virtually unchanged, but if there is no customer demand (towns to go), that is, there is no need to go to those towns, or the demand significantly increases, these routes become inefficient. In the first instance, it is inefficient because unnecessary routes are performed and, in the second one, a bigger vehicle fleet is required to meet such a demand so that new routes enforcing a series of restrictions related to the vehicles load and the associated cost to each route (in time and maximum distance) need to be established. These routes could be predetermined in a static way, but it is also necessary to make the time for each route as homogeneous as possible to avoid greater workloads for the driving staff.

This work presents two simulations:

1. Villages without demand: Calculations for dynamic routes were evaluated against the fixed ones presented for one vehicle through one year (52 weeks). A probability and a restriction were established: the probability of whether or not going to a town every week based on the population of those towns and, as restriction, the need to go to a town at least once every three weeks to maintain the contact with the customers living there.

2. Variable demand depending on the population: Three demand scenarios were established. For each one, simulations were performed and the results of using dynamic routes were compared against the ones planned from a static approach-each vehicle fleet against itself. In this case study, population data of every town were collected using the Nominatim API [36].

\section{Results}

This section presents and discussed the results of the two case study simulations and lastly the results of the implementation of the Voice Assistant Agent.

\subsection{Villages without Demand}

The delivery of orders along 52 consecutive weeks was compared using a dynamic route calculation approach versus a fixed route. The towns on each of the company routes established for each day of the week were maintained. The town demand was proposed to be unitary and homogeneous for all of them to verify savings exclusively resulting from not going to them if they do not present any demand. 
For the simulation, when establishing whether or not these towns should be visited, the following probability criteria (Equation (1)) to visit a town depending on its population was established.

$$
P(\text { visitTown })=0.5+\left(\frac{\text { townPopulation }}{75 \text { townpopulationpercentil }}\right) * 0.5
$$

The probability of visiting or not visiting a town increased from $50 \%$ according to the population of each one. In addition, it was established as a restriction that a town must be visited at least once every three weeks to maintain the company's contact with that population. A single vehicle was established for the simulations. The or-tools framework [40] was used together with the parameters employed in the solver to calculate solutions shown below (Table 2).

Table 2. Solver parameters.

\begin{tabular}{ccc}
\hline Parameter & Description & Value \\
\hline firstSolutionStrategy & Method employed to find the first solution & Parallel_cheapest_insertion \\
LocalSearchMetaheuristic & Local search strategy selected & guided_local_search \\
timeLimit & Solution search time limit & 5 min \\
\hline
\end{tabular}

The savings derived from avoiding trips to certain towns without demand were evaluated with the calculation of dynamic routes for each of the sets of villages in Soria and Burgos described above. Figures 10 and 11 show the results of the 52 simulated delivery weeks for each of the sets of villages on the routes described above. In these figures each of the bars represents the total distance in kilometers for each week against the red horizontal line showing the fixed cost of the static approach.

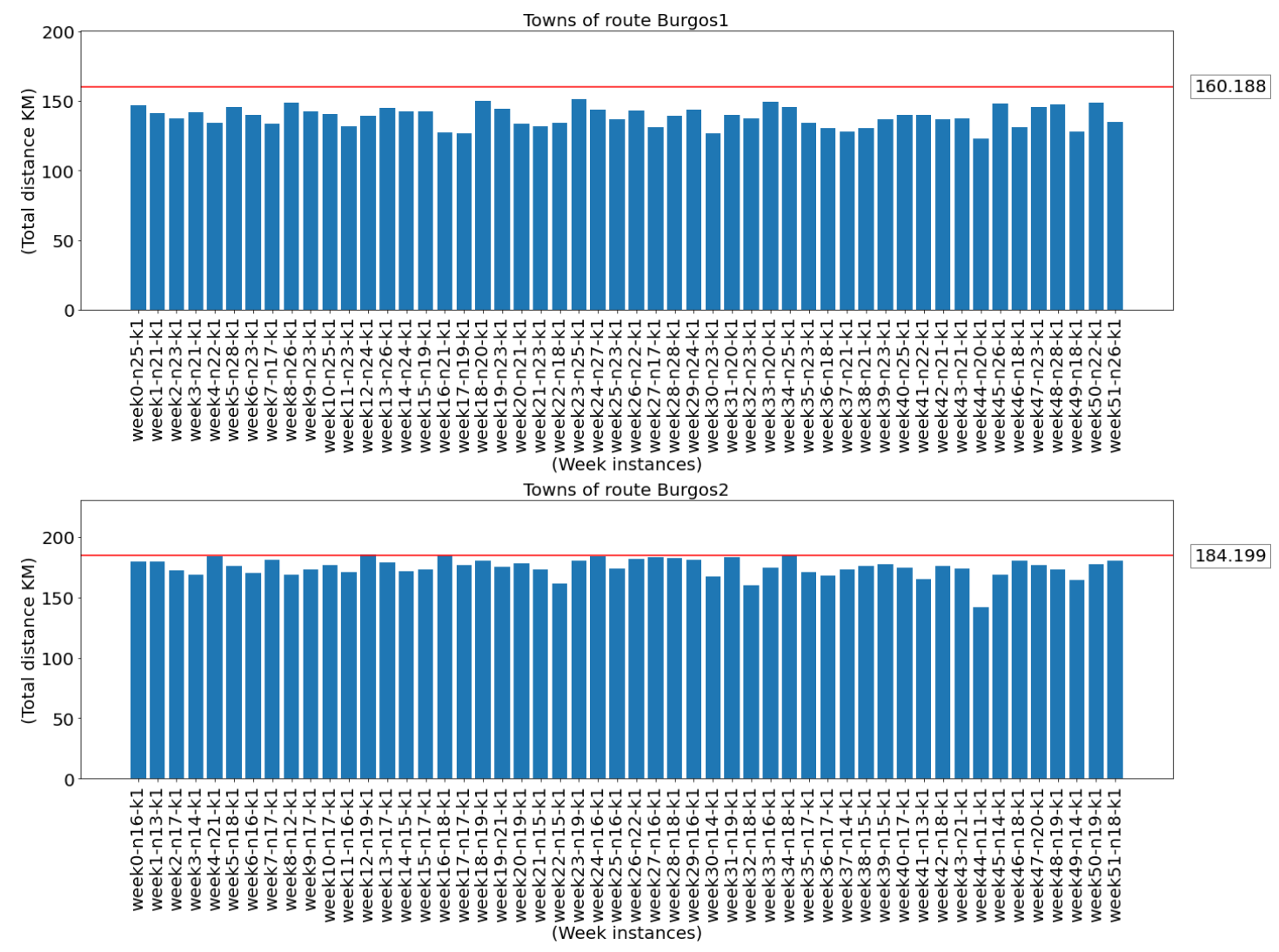

Figure 10. Simulation of 52 deliveries over a year comparing static and dynamic approach on Burgos routes. 

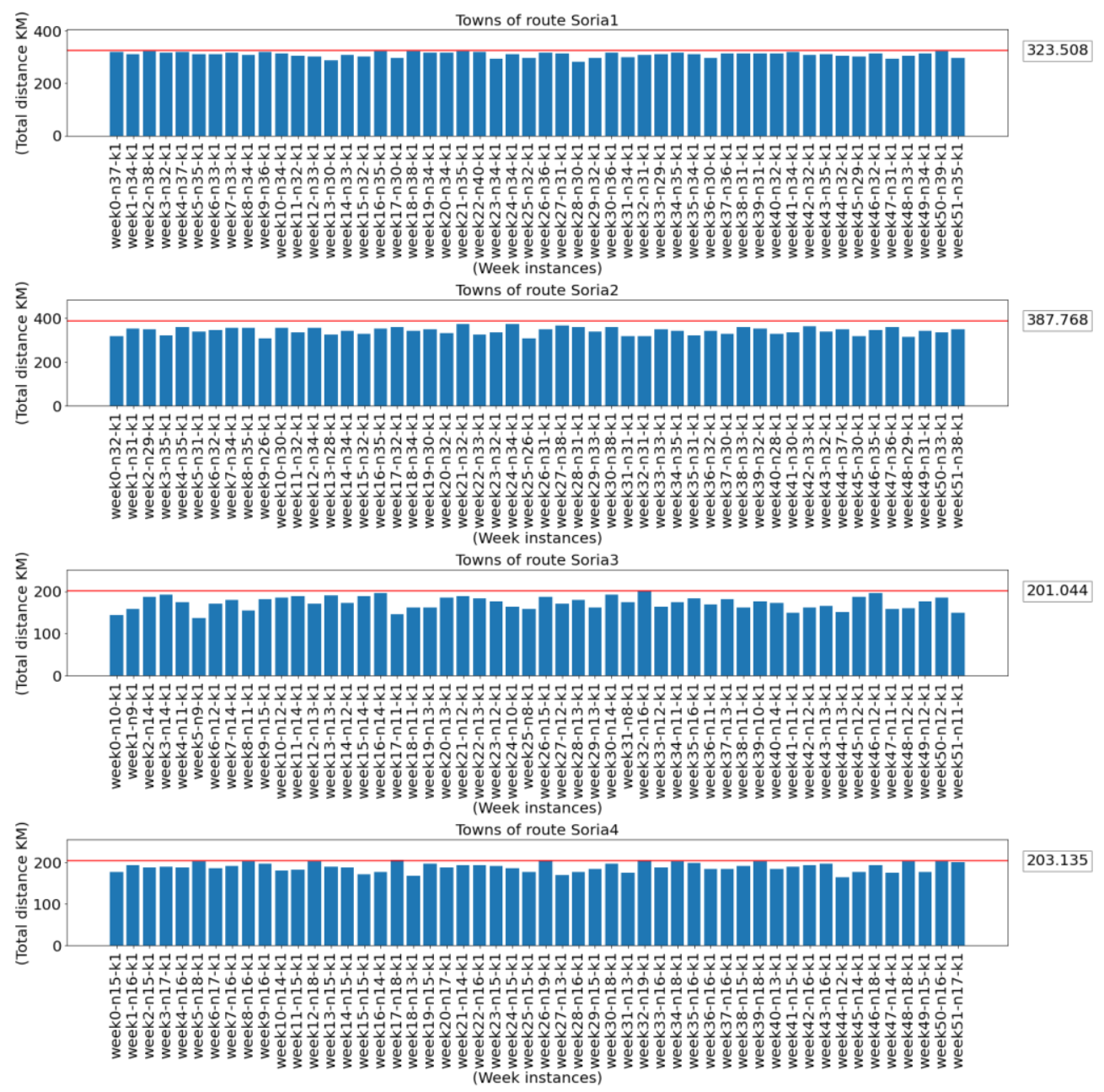

Figure 11. Simulation of 52 deliveries over a year comparing static and dynamic approach on Soria routes.

Table 3 shows the total annual travel costs in $\mathrm{km}$ for the fixed routes compared to the total cost by taking the costs of the simulations for each delivery week. The differences were between $4.45 \%$ and $14.05 \%$ per year of the total travel cost for the fixed route.

Table 3. Results of total distance per year employing fixed routes and dynamic routes.

\begin{tabular}{cccc}
\hline Ruta & $\begin{array}{c}\text { Fixed Routes } \\
\text { Distance }(\mathbf{k m}) \text { per Year }\end{array}$ & $\begin{array}{c}\text { Dynamic Routes } \\
\text { Distance } \mathbf{( k m}) \text { per Year }\end{array}$ & \% of Savings ${ }^{\mathbf{1}}$ \\
\hline Burgos1 & 8329.78 & 7211.76 & 13.42 \\
Burgos2 & 9578.35 & 9088.47 & 5.11 \\
Soria1 & $16,822.42$ & $16,073.15$ & 4.45 \\
Soria2 & $20,163.94$ & $17,764.80$ & 11.90 \\
Soria3 & $10,454.29$ & 8985.79 & $\mathbf{1 4 . 0 5}$ \\
Soria4 & $10,563.02$ & 9807.47 & 7.15 \\
\hline
\end{tabular}

${ }^{1}$ The minimum and maximum $\%$ of Savings have been highlighted.

These savings may not be very significant since, in this specific case, maintaining regular contact with the clients' location is necessary to maintain the clientele. After the results obtained, not visiting certain towns can mean a not very significant saving and at the same time a loss of contact with the end customer, so the company must properly assess the option to stop visiting villages without demand. 


\subsection{Variable Demand Depending on the Population}

This simulation addressed the optimization and dynamic calculation of delivery routes versus the static approach when the demand from towns varies. The region of Burgos was selected for this case study and the subsets of towns Burgos1 and Burgos2 were studied. For this purpose, three conditions were specified to perform the simulation of distribution scenarios.

Initially, for the static approach, fixed routes were established for each set of villages described above and a homogeneous fleet of vehicles was employed. This resulted in a different number of vehicle routes depending on the demand, i.e., if a single vehicle could cover the entire demand of the problem a route would be calculated, if two vehicles were needed two routes were established, and so forth. In this way, depending on the total amount of demand for the problem in question, a different number of routes would have to be used, all of which were fixed in advance assuming equal demand in each town.

Subsequently, 1000 instances were simulated for each of the demand scenarios described above, so that a random percentage of the population of each town was obtained as demand among the values described in Table 4. These instances were resolved using a dynamic approach, calculating the best solution for the VRP problem instance using the parameters in Table 5. Similarly, pre-established fixed routes were used to evaluate what it would cost to solve such instances using those routes.

Table 4. Demand scenarios considered for the simulation of the case study.

\begin{tabular}{cc}
\hline Scenario & \% Population \\
\hline Low & {$[1-5]$} \\
Medium demand & {$[5-10]$} \\
High demand & {$[10-15]$} \\
\hline
\end{tabular}

Table 5. VRP parameters and constraints.

\begin{tabular}{cc}
\hline Parameter & Value \\
\hline Vehicle max time & $10 \mathrm{~h}$ \\
Service time per order ${ }^{1}$ & $5 \mathrm{~min}$ \\
Car profile $^{2}$ & $90 \mathrm{~km} / \mathrm{h}$ \\
Car capacity $^{2}$ & 50 orders \\
\hline
\end{tabular}

${ }^{1}$ With a homogeneous cost. ${ }^{2}$ Capacity expressed in amount of orders.

Figure 12 shows the results obtained after the simulations for each group of towns in the Burgos routes, for each demand scenario, comparing the distance in $\mathrm{km}$ of dynamically generated routes with the routes of the static approach initially set. The demand parameters together with the above mentioned constraints can be seen to cause at least two vehicles to be needed in the solutions obtained. Likewise, as in the previous case study, it is possible to see the savings produced compared to a static approach. In this case it is possible to see how this saving becomes more evident when the demand is higher. In the same figure it is possible to observe the fixed costs in distance as a horizontal line, since the distance of the all routes in the static approach does not change, versus the variable costs presented by the dynamic approach, the latter being lower in most situations. In the results for this case study, it can be seen how, when faced with a significant variation in demand, dynamic route calculation becomes a necessary tool to reduce travel costs.

Figure 13 shows the results of total route times. For the static approach, the travel time and the service time that the route would have in each of the instances generated in the simulation was calculated. In this image, it is possible to observe how in scenarios with low demand the times can become similar, since the fixed routes have been set with an equitable demand. It is possible to highlight, as in the previous figure, time savings in many cases with this dynamic route calculation. 


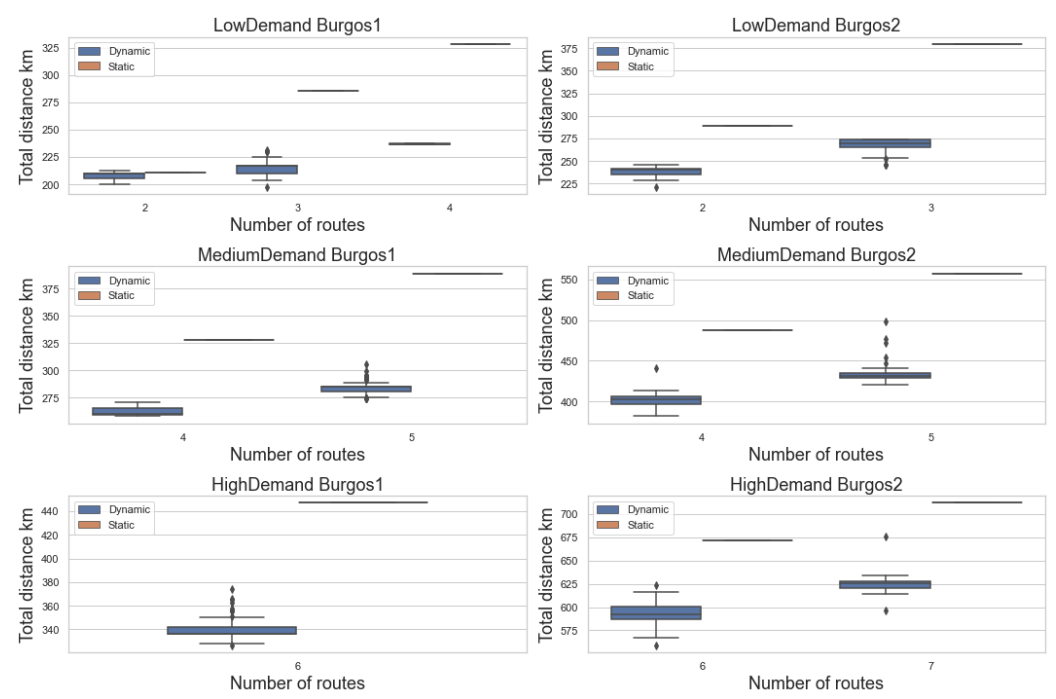

Figure 12. Comparison of total distance between dynamic and static approach under the three different demand scenarios.
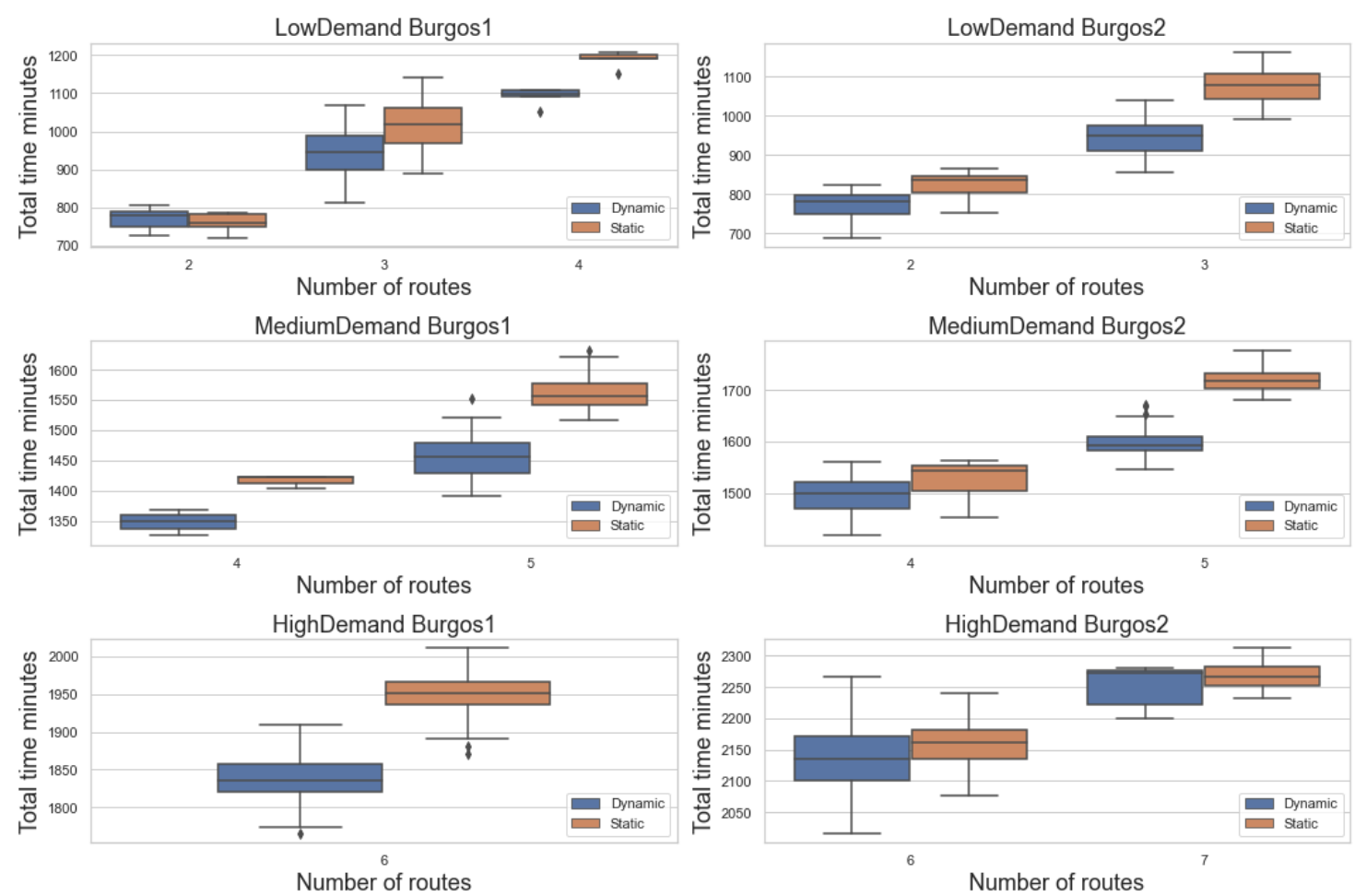

Figure 13. Comparison of total time between dynamic and static approach under different the three demand scenarios.

Finally, Figure 14 shows the results obtained from the service times of each of the routes of the solutions obtained. Using a static approach that takes demand into account will lead to very uneven routes causing problems in the shifts of the drivers in the fleet and resulting cost surpluses. The dynamic approach applying the restrictions mentioned above allows the calculated routes to be more homogeneous and not to affect the drivers of the vehicle fleet. 

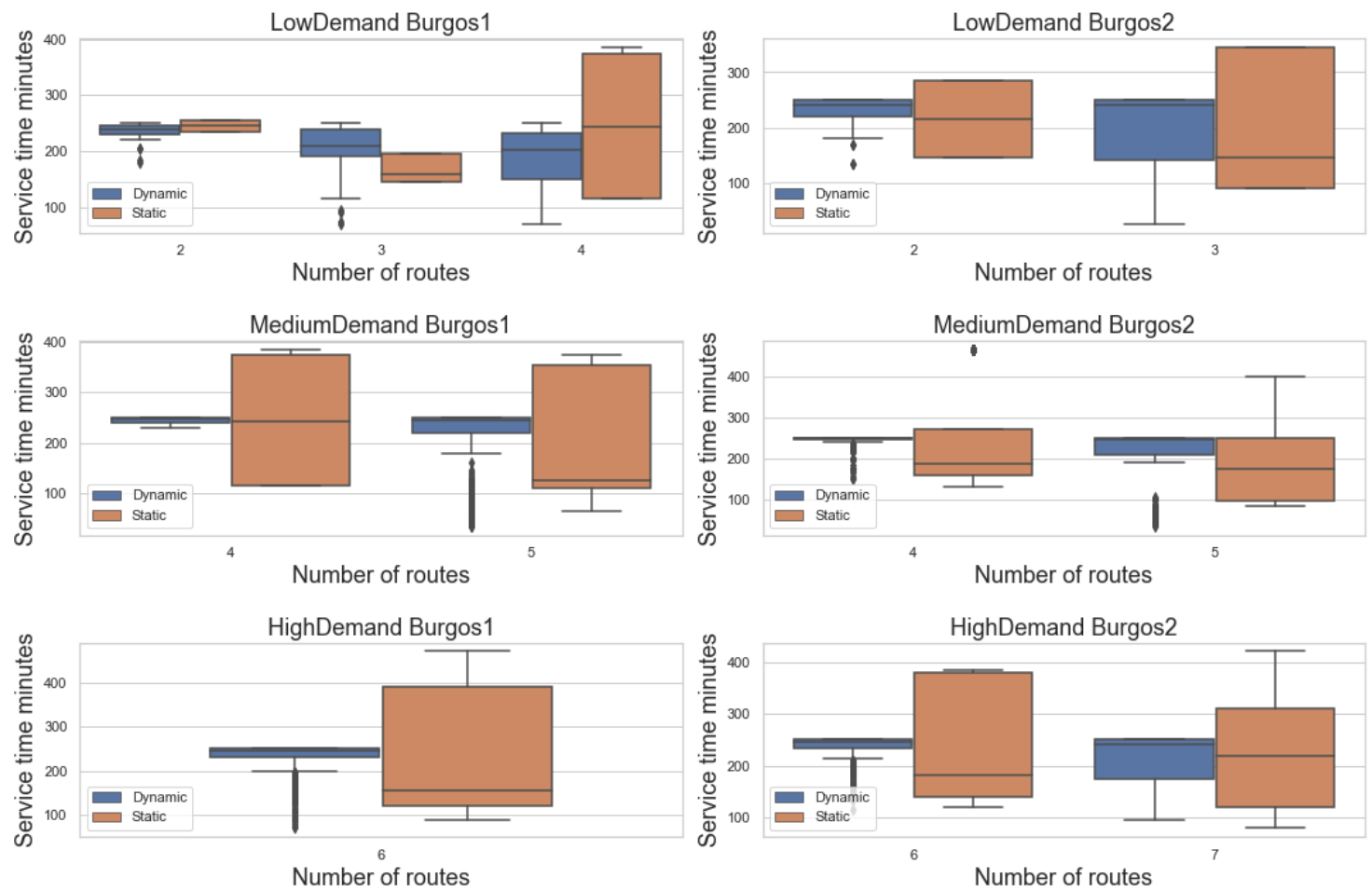

Figure 14. Comparison of individual service time of routes between dynamic and static approach under different the three demand scenarios.

\subsection{Results Voice Assistant}

Regarding the use of IPA as a means to place orders, it has been designed and developed employing feedback provided by people ageing between 65 and 83 years old. Initially, the conversation designed included the specification of every product thoroughly. After performing the first tests with this kind of dialogue, conversations between the users and the assistant were concluded as too long and complex to place an order. For this reason, a simple conversation approach has been applied to allow the IPA use in devices without a screen (Figure 15a) as well as in screen-equipped devices (Figure 15b), while keeping a shopping list structure. The use of devices with voice assistant and the built-in screen could be useful for other use cases where visual content is highly relevant to the user.

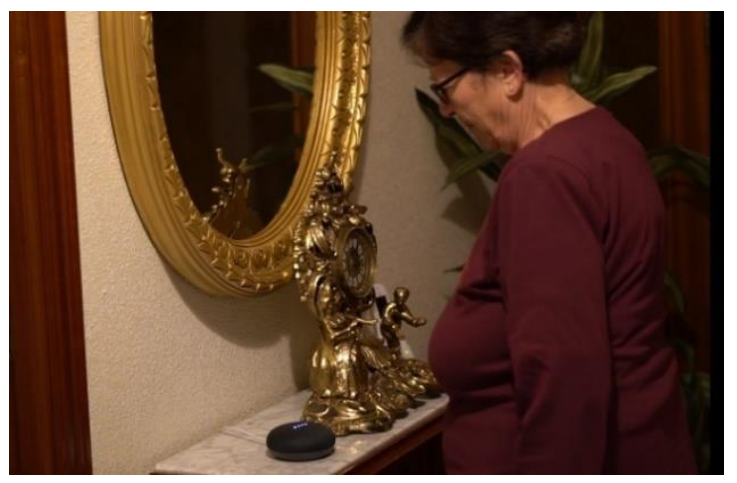

(a)

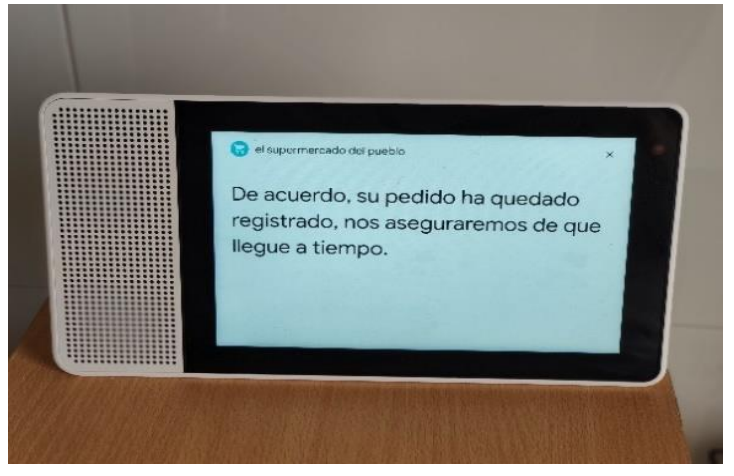

(b)

Figure 15. Intelligent Personal Assistant (IPA) order tests in an older adult home (a) without screen (b) with screen. 
This aims to perform a future study more exhaustive with customers of a company like the one described in the case study of this work, as well as exploit the advantages of screen-equipped devices to add more information when selecting products.

\section{Conclusions}

After developing the work presented in this paper, different conclusions have been drawn regarding each of the parts addressed in the system and the results of the case study.

The improvement of access to available services as well as the good delivery networks in depopulated rural areas is an issue that needs to be addressed so that these areas remain attractive places to live.

Likewise, enhancing the use of ICTs by the aged population is a challenge that it is required to be addressed with technologies that present a simple interface, like IPAs, which are a very friendly solution for the digital divide. IPAs have a great potential to reduce the age gap for older adults who have not been exposed to digital media for life and have difficulties incorporating them into their lives.

The use of this type of technology would allow logistics companies to employ new channels for receiving orders plus the ones that they already have, facilitating the access of these people to services and automating the process for the company.

On the other hand, delivery companies in rural areas seeking to continue to provide services to these areas should optimize the costs associated with the routes they take, while being able to cope with changes in customer demand.

In the case study of this work, the simulations carried out confronted a delivery approach with fixed routes versus the proposed dynamic approach using the application presented.

The first simulation showed savings between $4.45 \%$ and $14.05 \%$ of the total distance and that means not visiting certain towns on the delivery route at most every three weeks. This makes it possible to establish a trade-off between the contact with customers in these depopulated areas and the savings from the routes. This simulation showed that the dynamic approach offers savings in the routes maintaining the contact with the town at least one time every three weeks. For this reason, the company could benefit from savings on routes while maintaining contact with their customers.

The second simulation showed how the static approach of fixed routes, for a delivery company that meets a variable demand, means the realization of very different work routes for each of the workers and emphasized the need for a route optimization system that limits the maximum route that can be made by each distributor and that distributes the load evenly among workers. In the results obtained, pre-established fixed delivery routes were compared with dynamically calculated routes based on the specific demand of each scenario. It is possible to see how the calculation of routes in a dynamic way in the proposed scenarios facilitates the distribution of the workload while optimizing the distance traveled by the vehicles. This allows the company to be able to respond to a variable demand and save costs in distance, time, and personnel deliveries. The use of this type of system in socially-oriented logistics companies becomes a necessity with high variable demand to reduce the service cost and keep the viability of the business model.

Regarding the use of IPAs as a means of receiving orders in the proposed system, strengths have been found if the design of the conversation is simple and items ordered are not exhaustively specified. At the same time, there is a lack of proactivity in these types of assistants, as the user always has to interact with them first, limiting the possibility of notifying aged people with certain information proactively, without them having to make the query.

Although the results obtained from testing the voice assistant agent have been satisfactory, a study with a large number of aged people is needed to be able to evaluate this communication interface in the operation of a company like the one described in this work. At the same time, different limitations in the use of these assistants have been found in the development in rural areas due to the limitations of Internet access in these areas. These limitations could be overcome with investment in infrastructure and digitization. 
As research directions, new restrictions in the route calculation are included and the application developed would be implemented in the system of a logistics company, in a real operating environment. This would make it possible to contrast the savings produced by the route optimization system with the simulations of this study. Regarding the use of IPAs with aged people, conducting a study with the clients of this company to evaluate the adaptation to this new form of communication and its effectiveness in the daily life of older adults.

Author Contributions: Á.L.M. and D.M.J.-B. conceived and designed the proposed system and the voice assistant applications. G.L.L., A.V.R. and D.P.M. have contributed equally to the implementation of the voice assistant agent, the progressive web application and to the development of route optimization cloud services. A.L.M. has performed the simulation studies of route optimization and wrote the paper. A.L.M. reviewed and supervised the whole work. All authors have read and agreed to the published version of the manuscript.

Funding: This research was funded by CENIE and Fundación General Universidad de Salamanca in the project EMERITI granted by ALIANZA GENERACIONAL 2019.

Acknowledgments: Álvaro Lozano research work is supported by a postdoctoral fellowship from the University of Salamanca and Banco Santander. The research of Diego M. Jiménez-Bravo has been co-financed by the European Social Fund and Junta de Castilla y León (Operational Programme 2014-2020 for Castilla y León, EDU/574/2018 BOCYL). We would like to thank the company La Exclusiva for the data available online that has been used to carry out the case studies.

Conflicts of Interest: The authors declare no conflict of interest.

\section{References}

1. Gordon, M. Ageing Europe. Available online: https:/ec.europa.eu/eurostat/cache/digpub/ageing/ (accessed on 18 February 2020).

2. Elderly Population across EU Regions-Product-Eurostat. Available online: https://ec.europa.eu/eurostat/ web/products-eurostat-news/-/DDN-20200402-1 (accessed on 20 May 2020).

3. ESPON Fighting Rural Depopulation in Southern Europe. Transnatl:: Outreach Support. 2018. Available online: https://www.espon.eu/sites/default/files/attachments/af-espon_spain_02052018-en.pdf (accessed on 20 May 2020).

4. Negreiro, M. "Bridging the digital divide in the EU." EPRS-European Parliamentary Research Service, ENPE 573.884, Briefing. December 2015. Available online: https://www.europarl.europa.eu/RegData/etudes/ BRIE/2015/573884/EPRS_BRI(2015)573884_EN.pdf (accessed on 20 May 2020).

5. The European Network for Rural Development (ENRD)|Connecting Rural Europe. Available online: https://enrd.ec.europa.eu/ (accessed on 20 May 2020).

6. European Commission WiFi4EU-WIFI GRATIS PARA LOS EUROPEOS. Available online: http://ec.europa. eu/newsroom/dae/document.cfm?doc_id=41940 (accessed on 20 January 2020).

7. Julio, N.-M.; Raquel, P.-L.; Manuel, R.-G.L.; Julio, N.-M.; Raquel, P.-L.; Manuel, R.-G.L. Analysis of the WiFi4EU Initiative as a Potential Instrument to Correct Digital Divide in Rural Areas in the EU; International Telecommunications Society (ITS): Calgary, AB, Canada, 2019.

8. Reis, A.; Paulino, D.; Paredes, H.; Barroso, J. Using intelligent personal assistants to strengthen the elderlies' social bonds: A preliminary evaluation of amazon alexa, google assistant, microsoft cortana, and apple siri. In Proceedings of the Lecture Notes in Computer Science (including subseries Lecture Notes in Artificial Intelligence and Lecture Notes in Bioinformatics), Vancouver, BC, Canada, 9-14 July 2017; Springer: Berlin, Germany, 2017; Volume 10279 LNCS, pp. 593-602.

9. O’Brien, K.; Liggett, A.; Ramirez-Zohfeld, V.; Sunkara, P.; Lindquist, L.A. Voice-Controlled Intelligent Personal Assistants to Support Aging in Place. J. Am. Geriatr. Soc. 2020, 68, 176-179. [CrossRef] [PubMed]

10. De Barcelos Silva, A.; Gomes, M.M.; Da Costa, C.A.; Da Rosa Righi, R.; Barbosa, J.L.V.; Pessin, G.; De Doncker, G.; Federizzi, G. Intelligent personal assistants: A systematic literature review. Expert Syst. Appl. 2020, 147, 113193. [CrossRef]

11. McLean, G.; Osei-Frimpong, K. Hey Alexa ... examine the variables influencing the use of artificial intelligent in-home voice assistants. Comput. Hum. Behav. 2019, 99, 28-37. [CrossRef] 
12. Kowalski, J.; Skorupska, K.; Kopeć, W.; Jaskulska, A.; Abramczuk, K.; Biele, C.; Marasek, K. Older adults and voice interaction: A pilot study with google home. In Proceedings of the Human Factors in Computing Systems, Glasgow, UK, 3 May 2019; Association for Computing Machinery: New York, NY, USA, 2019; pp. 1-6.

13. FPCIW Front Porch Center for Innovation and Wellbeing Releases Results of Amazon Alexa Pilot Project in San Diego Retirement Community-Front Porch Center for Innovation and Wellbeing. Available online: https://fpciw.org/news/front-porch-center-for-innovation-and-wellbeing-releases-resultsof-amazon-alexa-pilot-project-in-san-diego-retirement-community/ (accessed on 8 July 2019).

14. Reis, A.; Paulino, D.; Paredes, H.; Barroso, I.; Monteiro, M.J.; Rodrigues, V.; Barroso, J. Using intelligent personal assistants to assist the elderlies An evaluation of Amazon Alexa, Google Assistant, Microsoft Cortana, and Apple Siri. In Proceedings of the TISHW 2018-2nd International Conference on Technology and Innovation in Sports, Health and Wellbeing, Thessaloniki, Greece, 20-22 June 2018; Institute of Electrical and Electronics Engineers (IEEE): Piscataway, NJ, USA, 2018.

15. Dantzig, G.B.; Ramser, J.H. The Truck Dispatching Problem. Manag. Sci. 1959, 6, 80-91. [CrossRef]

16. Braekers, K.; Ramaekers, K.; Van Nieuwenhuyse, I. The vehicle routing problem: State of the art classification and review. Comput. Ind. Eng. 2016, 99, 300-313. [CrossRef]

17. Kumar, S.N.; Panneerselvam, R. A Survey on the Vehicle Routing Problem and Its Variants. Intell. Inf. Manag. 2012, 04, 66-74. [CrossRef]

18. Wang, S.; Tao, F.; Shi, Y.; Wen, H. Optimization of Vehicle Routing Problem with Time Windows for Cold Chain Logistics Based on Carbon Tax. Sustainability 2017, 9, 694. [CrossRef]

19. Jiang, J.; Ng, K.M.; Poh, K.L.; Teo, K.M. Vehicle routing problem with a heterogeneous fleet and time windows. Expert Syst. Appl. 2014, 41, 3748-3760. [CrossRef]

20. Tasan, A.S.; Gen, M. A genetic algorithm based approach to vehicle routing problem with simultaneous pick-up and deliveries. Comput. Ind. Eng. 2012, 62, 755-761. [CrossRef]

21. Baldacci, R.; Mingozzi, A.; Roberti, R. Recent exact algorithms for solving the vehicle routing problem under capacity and time window constraints. Eur. J. Oper. Res. 2012, 218, 1-6. [CrossRef]

22. Laporte, G.; Nobert, Y. A branch and bound algorithm for the capacitated vehicle routing problem. OR Spektrum 1983, 5, 77-85. [CrossRef]

23. Lysgaard, J.; Wøhlk, S. A branch-and-cut-and-price algorithm for the cumulative capacitated vehicle routing problem. Eur. J. Oper. Res. 2014, 236, 800-810. [CrossRef]

24. Nagata, Y.; Bräysy, O. A powerful route minimization heuristic for the vehicle routing problem with time windows. Oper. Res. Lett. 2009, 37, 333-338. [CrossRef]

25. Zhang, X.; Tang, L. A new hybrid ant colony optimization algorithm for the vehicle routing problem. Pattern Recognit. Lett. 2009, 30, 848-855. [CrossRef]

26. Maher, M.; Puget, J.-F. (Eds.) Principles and Practice of Constraint Programming-CP98; Lecture Notes in Computer Science; Springer: Berlin/Heidelberg, Germany, 1998; Volume 1520, ISBN 978-3-540-65224-3.

27. Shaw, P. Using Constraint Programming and Local Search Methods to Solve Vehicle Routing Problems. Computer (Long. Beach. Calif). 1998, 1520, 417-431.

28. Alvarenga, G.B.; Mateus, G.R.; De Tomi, G. A genetic and set partitioning two-phase approach for the vehicle routing problem with time windows. Comput. Oper. Res. 2007, 34, 1561-1584. [CrossRef]

29. Rochat, Y.; Taillard, É.D. Probabilistic diversification and intensification in local search for vehicle routing. J. Heuristics 1995, 1, 147-167. [CrossRef]

30. Barbarosoglu, G.; Ozgur, D. A tabu search algorithm for the vehicle routing problem. Comput. Oper. Res. 1999, 26, 255-270. [CrossRef]

31. Google Google OR-Tools. Available online: https://developer.linkedin.com/\%0Ahttps://developers.google. com/glass/overview\%0Ahttps://developers.google.com/ (accessed on 10 May 2019).

32. VROOM-Vehicle Routing Open-Source Optimization Machine. Available online: http://vroom-project.org/ (accessed on 10 June 2020).

33. Salvi, S.; Geetha, V.; Sowmya Kamath, S. Jamura: A Conversational Smart Home Assistant Built on Telegram and Google Dialogflow. In Proceedings of the IEEE Region 10 Annual International Conference, Proceedings/TENCON, Kochi, India, 17-20 October 2019; Institute of Electrical and Electronics Engineers (IEEE): Piscataway, NJ, USA, 2019; pp. 1564-1571. 
34. Fernandes, S.; Gawas, R.; Alvares, P.; Femandes, M.; Kale, D.; Aswale, S. Survey on Various Conversational Systems; Institute of Electrical and Electronics Engineers (IEEE): Piscataway, NJ, USA, 2020; pp. 1-8.

35. Fortunato, D.; Bernardino, J. Progressive web apps: An alternative to the native mobile Apps. In Proceedings of the Iberian Conference on Information Systems and Technologies (CISTI), Caceres, Spain, 13-16 June 2018; IEEE Computer Society: Piscataway, NJ, USA, 2018; pp. 1-6.

36. OpenStreetMap Nominatim: Search. Available online: https://nominatim.openstreetmap.org/ (accessed on 1 June'2020).

37. Project OSRM. Available online: http://project-osrm.org/ (accessed on 26 June 2020).

38. Solving Vehicle Routing Problems with OpenStreetMap and VROOM. Available online: https://2018. stateofthemap.org/2018/T053-Solving_vehicle_routing_problems_with_OpenStreetMap_and_VROOM/ (accessed on 26 June 2020).

39. Available online: http://www.laexclusiva.org/wp-content/uploads/2017/01/dossier-prensa-la-exclusiva. compressed.pdf (accessed on 29 May 2020).

40. OR-Tools|Google Developers. Available online: https://developers.google.com/optimization/ (accessed on 11 May 2019).

(C) 2020 by the authors. Licensee MDPI, Basel, Switzerland. This article is an open access article distributed under the terms and conditions of the Creative Commons Attribution (CC BY) license (http://creativecommons.org/licenses/by/4.0/). 